\title{
Effect of Dew Period and Temperature on the Ability of Exserohilum monoceras to Cause Seedling Mortality of Echinochloa Species
}

\author{
W. M. Zhang, Graduate Research Assistant, and A. K. Watson, Professor, Department of Plant Science, Macdon- \\ ald Campus of McGill University, Montréal, Québec, Canada H9X 3V9; and Research Scholar and Weed Scientist \\ (seconded from McGill University), International Rice Research Institute, PO Box 933, 1099 Manila, Philippines
}

\begin{abstract}
Zhang, W. M., and Watson, A. K. 1997. Effect of dew period and temperature on the ability of Exserohilum monoceras to cause seedling mortality of Echinochloa species. Plant Dis. 81:629634.

In greenhouse and controlled environment experiments, disease development and mortality of Echinochloa crus-galli, E. colona, and E. glabrescens caused by Exserohilum monoceras were affected by duration, frequency, and timing of dew period, as well as by dew-period temperature and post-dew temperature. When adequate dew was provided, $100 \%$ mortality occurred for all three Echinochloa spp. over the broad dew-period temperature range of 20 to $30^{\circ} \mathrm{C}$. The effect of post-dew temperature on disease development varied with the initial dew period. The minimum dew period to achieve $100 \%$ mortality was $16 \mathrm{~h}$ for E. colona, $12 \mathrm{~h}$ for E. crus-galli, and 8 $\mathrm{h}$ for E. glabrescens. Increasing dew period enlarged the range of temperature for maximum efficacy, whereas the use of optimum dew-period temperature decreased the dew period requirement. Delaying the initiation of the dew period by $24 \mathrm{~h}$ did not adversely affect disease development. Increased disease development occurred for inoculated seedlings treated with repetitive dew periods of shorter duration than the optimal period. These findings characterize one of the epidemiological requirements, i.e., dew requirement, needed to assess the potential of $E$. monoceras for the control of Echinochloa spp. in rice.
\end{abstract}

Additional keywords: barnyard grass, bioherbicide, jungle rice, weed control

Barnyard grass, Echinochloa crus-galli (L.) Beauv., ranked as the world's third worst weed, is one of the most serious weeds in rice (Oryza sativa L.) $(2,7,18)$. Intense competition from E. crus-galli can reduce tillering in rice by up to $50 \%$ (7). Smith (17) reported that season-long competition from E. crus-galli reduced rice grain yields by $70 \%$. Jungle rice, E. colona (L.) Link., ranked as the world's fourth worst weed, is another serious weed in rice, especially in upland rice $(7,14)$. Yield reductions of $25 \%$ were observed in rice at E. colona densities of 80 plants $/ \mathrm{m}^{2}$ during the first 40 days of growth of this crop (12, $14)$. Although $E$. colona is a less vigorous competitor than E. crus-galli, E. colona poses serious problems in rice systems because populations typically far exceed 80 plants $/ \mathrm{m}^{2}$. E. glabrescens Munro ex Hook. f. is also an important weed species in rice, especially in tropical regions $(2,13)$. Average yield reductions in rice from transplanted E. glabrescens ranged from $6 \%$ at $5 \%$ infestation levels to $73 \%$ at $40 \%$ infestation levels (15).

Corresponding author: Alan K. Watson E-mail: watsona@agradm.lan.mcgill.ca

Accepted for publication 4 March 1997.

Publication no. D-1997-0407-04R

(C) 1997 The American Phytopathological Society
Various management strategies are available for suppression of Echinochloa spp. in rice, including cultural techniques, hand-weeding, mechanical control, and chemical herbicides (10). Currently, the possibility of using indigenous plant pathogens as biological control agents to control these Echinochloa spp. in rice is being investigated (24,31). A fungus, Exserohilum monoceras (Drechs.) K. J. Leonard \& E. G. Suggs, isolated from diseased Echinochloa spp. in the Philippines, caused blight symptoms on E. crus-galli, E. colo$n a$, and E. glabrescens, but was nonpathogenic to rice (31). An inoculum dose of 2.5 to $5.0 \times 10^{7}$ conidia $/ \mathrm{m}^{2}$ killed seedlings of Echinochloa spp. at the 1.5-leaf stage under greenhouse conditions (30).

Since infection, disease development, and, subsequently, weed control efficacy of pathogens are usually suppressed under natural conditions $(6,19,25)$, it is essential to determine optimal environmental conditions for disease development as well as limiting environmental factors that should be overcome or bypassed for effective field control of Echinochloa spp. by the fungus Exserohilum monoceras. Dew period and temperature have been recognized as two important environmental components that contribute to the efficacy of a bioherbicide $(19,26)$. Various studies of the effects of dew period and temperature on the efficacy of commercial and other potential bioherbicides have been reported and provided important information on epidemiological parameters $(9,11,20,23)$. Thus, the objective of this study was to evaluate the effect of dew period, frequency, and timing on infection, disease development, and virulence of Exserohilum monoceras on Echinochloa spp. The effects of dew-period temperature as well as post-dew temperature on disease development were also investigated.

\section{MATERIALS AND METHODS}

Inoculum production. A singleconidial isolate of Exserohilum monoceras, growing on half-strength potato dextrose agar (Difco, Detroit, MI) slants in small vials, was maintained under mineral oil at $4^{\circ} \mathrm{C}$ as the stock culture (22). Small pieces of mycelium from the stock culture were aseptically transferred to potato dextrose agar plates. Each plate was sealed with Parafilm (American National Can, Greenwich, CT) and incubated at $28^{\circ} \mathrm{C}$ for 7 days. Agar plugs (6 $\mathrm{mm}$ in diameter) containing mycelia were collected from the margins of these young colonies and used to inoculate lima bean agar plates. The lima bean agar plates were prepared by grinding $15 \mathrm{~g}$ of dry lima beans to a very fine powder, cooking in 1 liter of boiling water for $45 \mathrm{~min}$, and adding $10 \mathrm{~g}$ of agar. Seeded lima bean agar plates were sealed with Parafilm and incubated at $28^{\circ} \mathrm{C}$ in the dark for 3 weeks. Conidia were harvested from plates by flooding the plates with 10 $\mathrm{ml}$ of distilled water and scraping the surface of the colonies with a glass slide. The resulting suspension was filtered through a layer of cheesecloth. The inoculum concentration was determined with the aid of hemacytometer and adjusted to the desired density by adding distilled water.

Plant production. A single batch of seeds of each of E. crus-galli, E. colona, and E. glabrescens collected from field populations at the International Rice Research Institute (IRRI), Los Baños, Philippines, was used in all experiments. Seeds of each species were incubated in petri dishes on moistened filter paper at room temperature for $48 \mathrm{~h}$. Five germinated seeds (coleoptile and radicle visible) were planted in $10-\mathrm{cm}$-diameter plastic pots filled with water-saturated soil (Maahas clay, suborder Haplustic). Seeded pots were placed on a pushcart in the greenhouse, and a 2- to 3-cm water level was maintained throughout the experimental 
period. Greenhouse conditions were 35/23 $\pm 5^{\circ} \mathrm{C}$ day/night temperature, a 12 -h photoperiod, and average light intensity of 350 $\mu \mathrm{E} \mathrm{s}^{-1} \mathrm{~m}^{-2}$.

General inoculation procedure. Each treatment consisted of inoculating four pots of each of the three Echinochloa spp. (each pot containing five seedlings at the 1.5-leaf stage) with a conidial suspension at a rate of $5.0 \times 10^{7}$ conidia $/ \mathrm{m}^{2}$ containing $0.05 \%$ Tween 20 (polyoxymethylene sorbitan monolaureate, Sigma Chemical, St. Louis, MO) as a wetting agent, using a motorized sprayer at $100 \mathrm{kPa}$ (A. H. Thomas Co. Scimediately after inoculation, pots were transferred to a greenhouse section at $26 \pm$ $2^{\circ} \mathrm{C}$ and $90 \pm 5 \%$ relative humidity (27).

Assessment of disease development. Mortality of plants and dry weight of living aboveground biomass per pot were assessed 10 days after inoculation (DAI). Completely collapsed seedlings were considered dead. Dry weight was obtained by cutting aerial parts at soil level, drying the parts in paper bags for 4 to 5 days at $60^{\circ} \mathrm{C}$, and weighing. Dead tissue was not included in dry weight measurements. The dry weight data were expressed as percent reduction in biomass compared with the biomass of noninoculated controls.

Effect of dew-period temperature. After inoculation, pots with inoculated seedlings were placed in a dark dew chamber at temperatures of $10,15,20,25,30$, 35 , or $40 \pm 1{ }^{\circ} \mathrm{C}$ for $24 \mathrm{~h}$ and then returned to the greenhouse. entific Apparatus, Philadelphia, PA). Im-

Effect of post-dew temperature. Pots with inoculated seedlings were placed in a dark dew chamber at $25 \pm 1^{\circ} \mathrm{C}$ for either 12 or $24 \mathrm{~h}$. After the dew-period treatment, pots were transferred to growth chambers at temperatures of $15,20,25,30,35$, or 40 $\pm 1^{\circ} \mathrm{C}$, with a photoperiod of $12 \mathrm{~h}$ and light intensity of $300 \mu \mathrm{E} \mathrm{s}^{-1} \mathrm{~m}^{-2}$ for 10 days.

Effect of dew period. Pots with inoculated seedlings were placed in a dark dew chamber at $25 \pm 1^{\circ} \mathrm{C}$ for $0,4,8,12,16,20$, or $24 \mathrm{~h}$. Except for the 24-h treatment, all pots were covered with cardboard for the remainder of the $24 \mathrm{~h}$ to simulate the dark period in the dew chamber. After the dew period treatment, pots were returned to the greenhouse.

Interaction between dew-period temperature and duration. After inoculation, pots with inoculated seedlings were placed in a dark dew chamber at $15,20,25,30$, or $35 \pm 1^{\circ} \mathrm{C}$ and exposed to dew periods of 4 , $8,12,16,20$, or $24 \mathrm{~h}$. The experiment had a $5 \times 6$ factorial design. Except for the 24$\mathrm{h}$ treatment at each temperature, pots were covered with cardboard for the remainder of the $24 \mathrm{~h}$ to simulate the dark period in the dew chamber. Following the dewperiod treatment, pots were returned to the greenhouse.

Effect of delaying initial dew period. Pots with inoculated seedlings were placed in the greenhouse for $0,1,2,3$, or 4 days before being placed in a dark dew chamber for $4,8,12,16$, or $20 \mathrm{~h}$. The experiment had a $5 \times 5$ factorial design. Except for the 20-h treatment, pots removed from the dark dew chamber were covered with

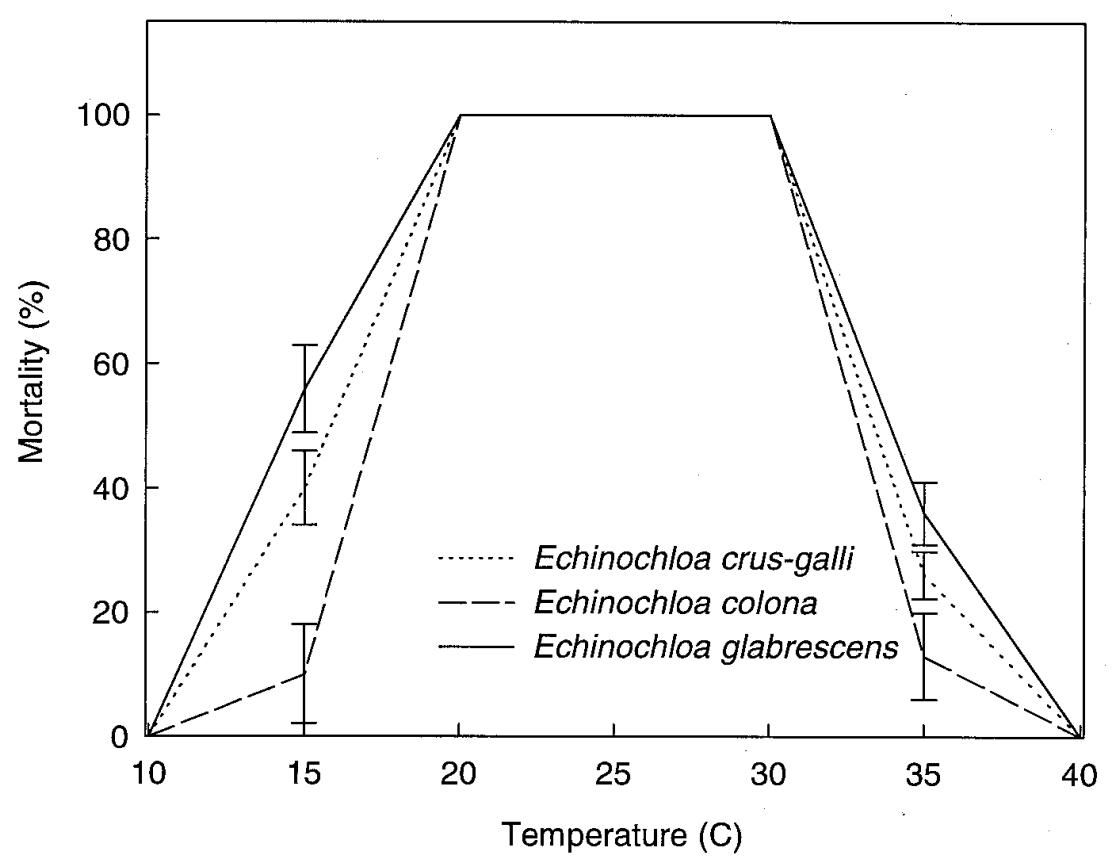

Fig. 1. Effect of dew-period temperature on disease development caused by Exserohilum monoceras on three Echinochloa spp., expressed as percent plant mortality 10 days after inoculation. Seedlings at the 1.5-leaf stage were sprayed with a conidial suspension of E. monoceras at rate of $5 \times 10^{7}$ con$\mathrm{idia} / \mathrm{m}^{2}$. Dew period was $24 \mathrm{~h}$. Data from two trials were pooled because variances were homogeneous. Points represent means of eight replicates. cardboard for the remainder of the $20 \mathrm{~h}$ to simulate the dark period in the dew chamber. After treatment, pots were returned to the greenhouse.

Effect of repetitive dew periods. Pots with inoculated seedlings were provided one of the following dark dew periods at $25 \pm 1{ }^{\circ} \mathrm{C}$ : (i) 6 -h dew period/18-h dry period on 1, 2, 3, or 4 consecutive days; (ii) 12-h dew period/12-h dry period on 1 or 2 consecutive days; or (iii) a single 24-h dew period. All pots were kept in the dark for the remainder of the $24 \mathrm{~h}$ to simulate the dark period in the dew chamber by covering pots with cardboard. After treatment, pots were returned to the greenhouse.

Data analyses. All experiments were performed twice. A randomized complete block design with four replicates was used for all experiments. All percent data were arc sine-transformed prior to analysis (5). Factorial experiments were analyzed with an analysis of variance considering the effect of each factor individually and their interaction. Regression analysis was performed on all significant $(\alpha \leq 0.05)$ dependent variables, using the PROC REG procedure in SAS (16). The best regression equation was selected with the step-wise model selection method (3). Results for the two trials of each experiment were pooled if homogeneity of variances was confirmed by the Bartlett test (5). However, for experiments in which the variances of trials were not homogeneous, results from one trial are presented given that a similar trend was observed in both trials. Mean values of five plants for each treatment were used for statistical analyses. Treatment means were separated by Duncan's multiple range test at the $5 \%$ level of significance.

\section{RESULTS}

Effect of dew-period temperature. All seedlings of E. crus-galli, E. colona, and E. glabrescens were killed at dew-period temperatures between 20 and $30^{\circ} \mathrm{C}$. However, mortality declined sharply when dew temperatures were below $20^{\circ} \mathrm{C}$ or above $30^{\circ} \mathrm{C}$ (Fig. 1). For example, at $15^{\circ} \mathrm{C}$ dew temperature, E. crus-galli, E. colona, and E. glabrescens mortalities were 40,10 , and $56 \%$, respectively, whereas with the $35^{\circ} \mathrm{C}$ dew-temperature treatment, E. crus-galli, E. colona, and E. glabrescens mortalities were 26,13 , and $36 \%$, respectively. No mortality was observed at a dew temperature of 10 or $40^{\circ} \mathrm{C}$ for any of the three Echinochloa spp.

Effect of post-dew temperature. The effect of post-dew temperature varied with the initial dew period (Fig. 2). When provided a 24-h dew period, all seedlings of the three Echinochloa spp. were killed at temperatures ranging from 15 to $40^{\circ} \mathrm{C}$. However, when provided a $12-\mathrm{h}$ dew period, mortality of the three Echinochloa spp. varied with different post-dew temperatures. The highest level of mortality of 
the three Echinochloa spp. was observed at the $30^{\circ} \mathrm{C}$ post-dew temperature treatment. Among the three Echinochloa spp., mortality of E. glabrescens appeared to be least influenced by post-dew temperature.

Effect of dew period. Mortality increased concomitantly as dew period increased (Fig. 3). No plant death was recorded for the 0- and 4-h dew period treatments. However, more than 8,12 , and $16 \mathrm{~h}$ of dew resulted in $100 \%$ mortality of $E$. glabrescens, E. crus-galli, and E. colona seedlings, respectively.

Interaction between dew-period temperature and duration. Mortality of all seedlings was observed with long dew period and dew-period temperatures of 20 to $30^{\circ} \mathrm{C}$ (Figs. 4 and 5). The minimum dew period for $100 \%$ mortality of E. crus-galli was $12 \mathrm{~h}$ at dew-period temperatures of 20 to $30^{\circ} \mathrm{C}$ (Fig. $4 \mathrm{~A}$ ). For E. colona, $100 \%$ mortality occurred with a minimum of $16 \mathrm{~h}$ of dew at dew-period temperatures of 20 and $25^{\circ} \mathrm{C}$, while a 20 -h dew period was needed for $100 \%$ mortality when the dewperiod temperature was $30^{\circ} \mathrm{C}$ (Fig. 4B). For E. glabrescens, the ranges of dew period and temperature for achieving the highest levels of control were similar to those of E. crus-galli, except that a $100 \%$ mortality of $E$. glabrescens was obtained after only an 8-h dew period at $25^{\circ} \mathrm{C}$ (Fig. 4C).

For the temperature range tested, the relationship between dew-period temperature and duration for attaining $100 \%$ mortality was similar for all three species, but E. glabrescens was most susceptible and $E$. colona least susceptible (Fig. 5). The predicted minimum dew period required to produce $100 \%$ mortality was $12.4,15.8$, and 9.9 h for E. crus-galli, E. colona, and E. glabrescens, respectively.

Effect of delaying initial dew period. The greatest seedling mortality for all three species was obtained following the shortest delay in providing a dew period (Fig. 6). When the initial dew period was delayed 1 day after inoculation, the 12 -h dew period treatment still resulted in $95 \%$ mortality of E. crus-galli, while the 16- and 20-h dew periods resulted in $100 \%$ seedling mortality. These mortality rates were not significantly different from those in which the 12- and 16-h dew period treatments were initiated immediately after inoculation. When the initial dew period was delayed by 2 days or longer after inoculation, $E$. crus-galli mortality decreased sharply (Fig. 6A). Similar patterns were observed for $E$. colona and E. glabrescens, with E. colona susceptibility more adversely affected by dew period delay than E. glabrescens susceptibility (Fig. 6B and C).

Effect of repetitive dew periods. When provided with a continuous dew period of $12 \mathrm{~h}$ or more, E. monoceras killed all $E$. crus-galli seedlings (Table 1). If two 6-h dew periods on consecutive days were pro- vided, no mortality occurred, but when $E$. crus-galli seedlings were exposed to four 6-h dew periods, E. monoceras caused nearly $70 \%$ mortality (Table 1). Even though E. monoceras did not cause $100 \%$ mortality when provided with a 6-h dew period on 2, 3, and 4 consecutive days, $E$. crus-galli dry weight was reduced from 43

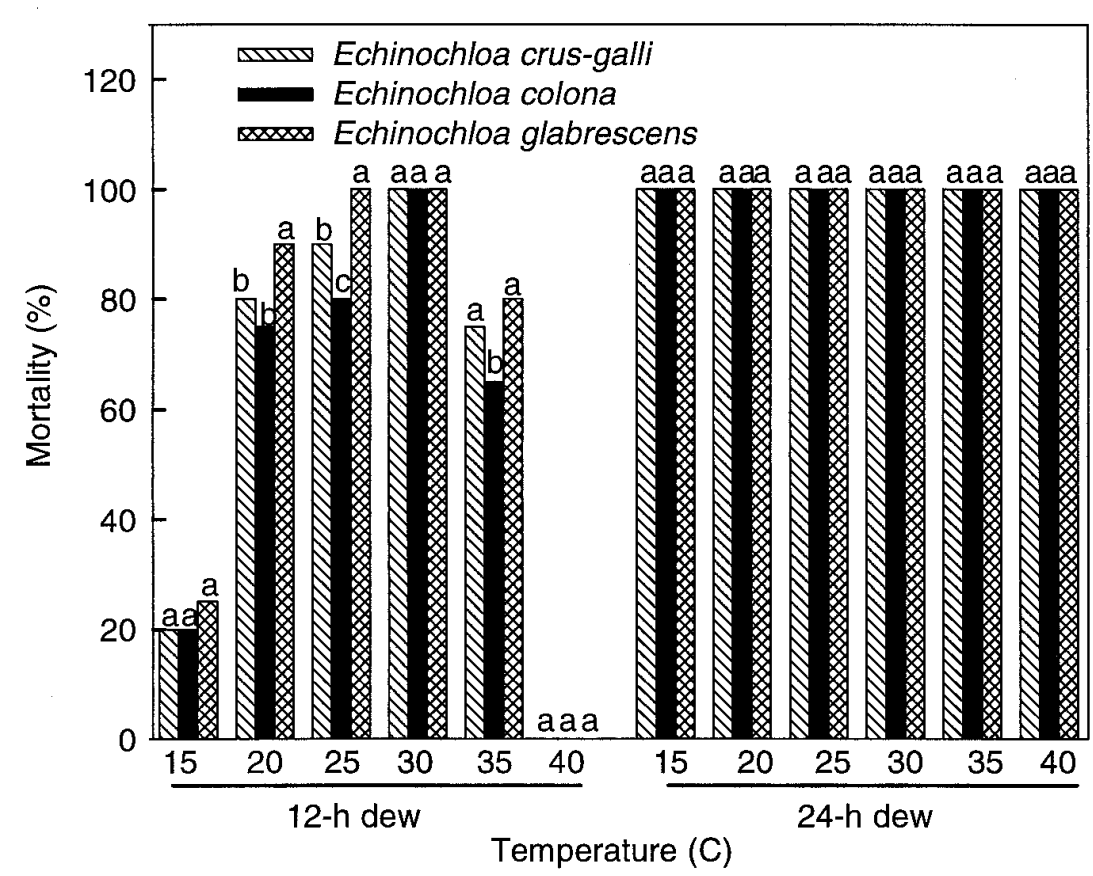

Fig. 2. Effect of post-dew temperature on disease development caused by Exserohilum monoceras on three Echinochloa spp., expressed as percent plant mortality 10 days after inoculation. Seedlings at the 1.5-leaf stage were sprayed with a conidial suspension of E. monoceras at a rate of $5 \times 10^{7}$ con$\mathrm{idia} / \mathrm{m}^{2}$ and given a $12-$ or $24-\mathrm{h}$ dew period. Data from two trials were not pooled because variances were not homogeneous. Bars represent means of four replicates. Bars within each temperature treatment in a dew period having the same letter are not significantly different according to Duncan's multiple range test at the $5 \%$ significance level.

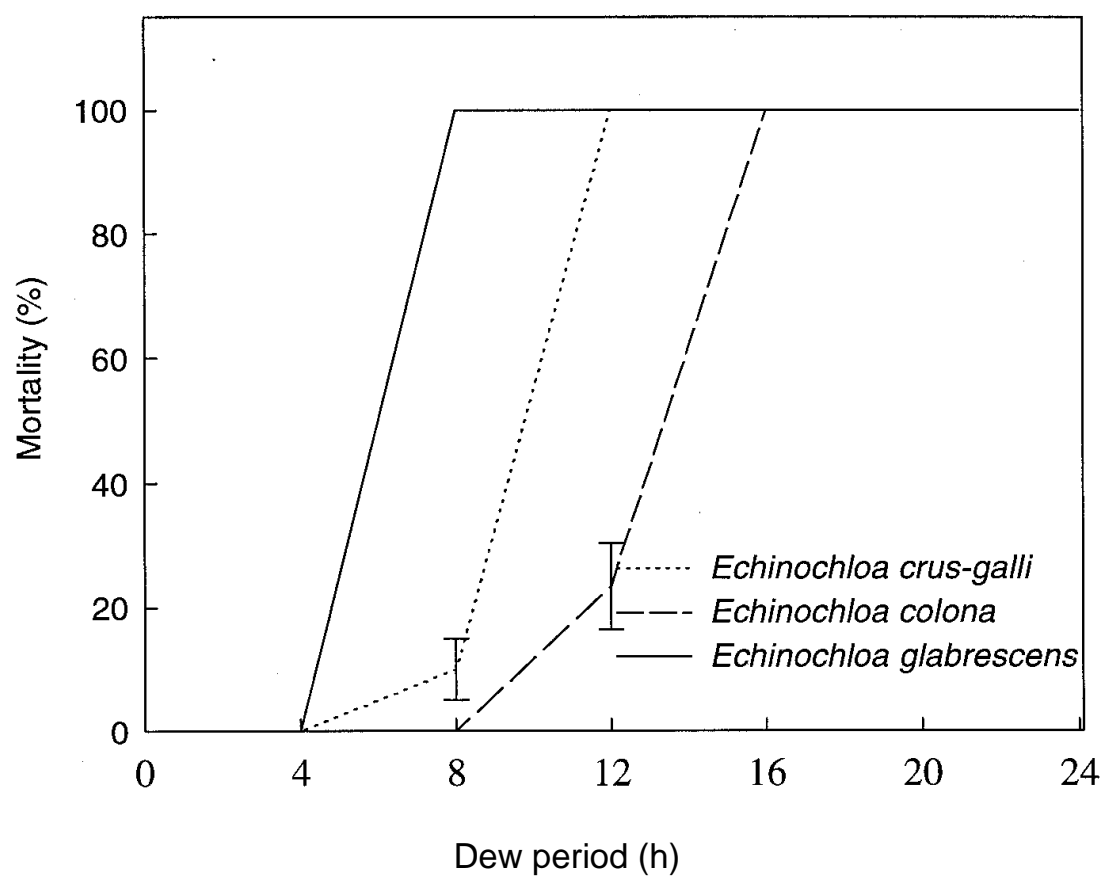

Fig. 3. Effect of dew period on disease development caused by Exserohilum monoceras on three Echinochloa species, expressed as percent plant mortality 10 days after inoculation. Seedlings at the 1.5-leaf stage were sprayed with a conidial suspension of E. monoceras at a rate of $5 \times 10^{7}$ con$\mathrm{idia} / \mathrm{m}^{2}$. Dew temperature was $25^{\circ} \mathrm{C}$ (in dark). Data from two trials were pooled because variances were homogeneous. Points represent means of eight replicates. 
to $90 \%$ (Table 1). Similar results were obtained with E. colona and E. glabrescens (data not shown).

\section{DISCUSSION}

Although the three Echinochloa spp. responded differently to $E$. monoceras at different dew-period temperatures, the optimum dew-period temperature range for achieving $100 \%$ mortality for all three
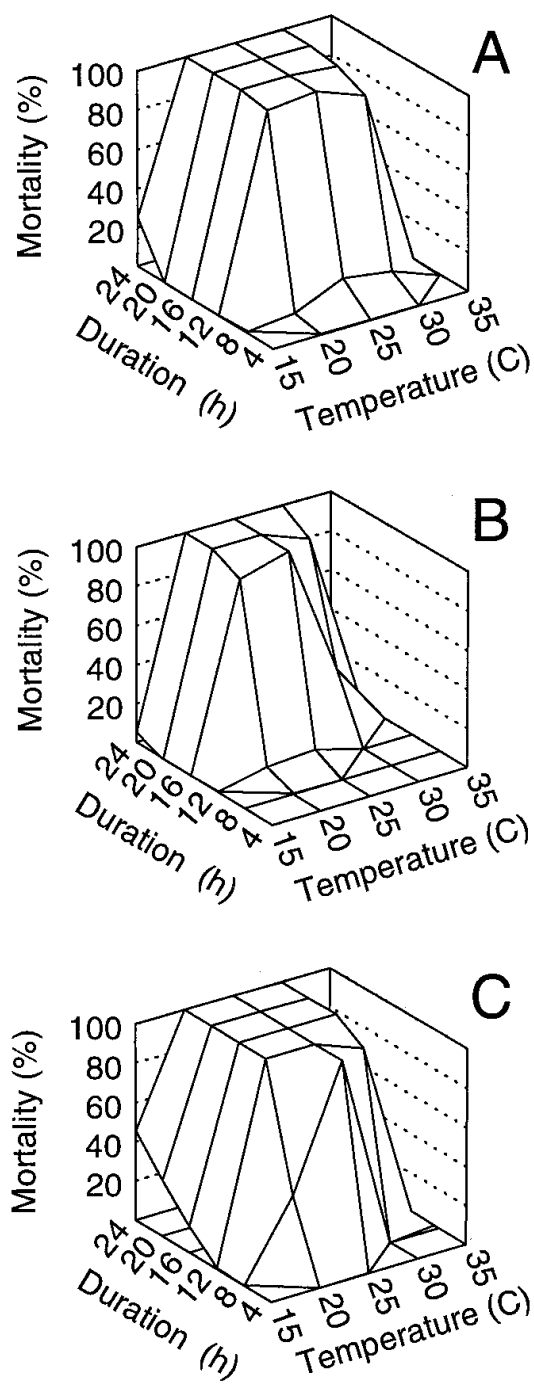

Fig. 4. Effect of dew-period temperature and duration on disease development caused by $E x$ serohilum monoceras on (A) Echinochloa crusgalli, (B) E. colona, and (C) E. glabrescens, expressed as percent plant mortality 10 days after inoculation. Data from two trials were pooled because variances were homogeneous. Points represent means of eight replicates. The relationships were best described by the following equations: (A) $Y=-45.82-15.71 D+$ $1.97 T D-0.04 T^{2} D-0.01 T D^{2}+T^{3}, r^{2}=0.7342$; (B) $Y=-474.01+42.17 T+0.67 D+2.06 T D-$ $1.93 T^{2}-0.76 D^{2}-0.05 T^{2} D+0.01 T D^{2}+0.03 T^{3}$, $r^{2}=0.8687$; and (C) $Y=-500.42+46.86 T+$ $9.40 \mathrm{D}-1.32 T^{2}-0.22 D^{2}+0.01 T^{3}, r^{2}=0.7434$; where $Y=$ mortality $(\%), T=$ dew-period temperature, and $D=$ dew period. Percent mortality data were arc sine-transformed before analysis.
Echinochloa spp. was similar (i.e., between 20 and $30^{\circ} \mathrm{C}$ ). Conflicting results have been reported with different bioherbicide pathosystems in which a single pathogen has been used to achieve control of more than one weed species. Boyette and Walker (1) reported that $25^{\circ} \mathrm{C}$ was the optimum dew-period temperature for the control of both Abutilon theophrasti Medik. (velvetleaf) and Sida spinosa L. (prickly sida) with Fusarium lateritium Nees:Fr., whereas the dew-period temperature that provided satisfactory control of Malva pusilla Smith (round-leaved mallow) by Colletotrichum gloeosporioides (Penz.) Penz. \& Sacc. in Penz. f. sp. malvae was less than that necessary to control A. theophrasti (9). Similar dewperiod temperature requirements for all three Echinochloa spp. should favor simultaneous, effective control on all three weedy Echinochloa spp. by E. monoceras. Moreover, the optimum dew-period temperature range and post-dew temperature for development of E. monoceras on Echinochloa spp. are within the temperature range that occurs during the rice-growing seasons in much of Southeast Asia (8), and are similar to temperatures required for conidial germination of E. monoceras (29). Therefore, dew-period temperature and post-dew temperature are not likely to be limiting factors for development of $E$. monoceras as a bioherbicide for the suppression of Echinochloa spp.
The effect of post-dew temperature may be related to the degree of initial infection, which is dependent upon the initial dew period. A 24 -h initial dew, at $25^{\circ} \mathrm{C}$ in the dark, appeared to allow E. monoceras to establish infections on Echinochloa spp. as shown by the similar degree of infection on the three Echinochloa spp. In this case, disease development does not appear to be affected by post-dew temperatures (from 15 to $40^{\circ} \mathrm{C}$ ). However, when the initial dew period was reduced to $12 \mathrm{~h}$, infection efficiency (28) on the three Echinochloa spp. differed and further disease development was influenced by post-dew temperature. Infection efficiency was greatest for E. glabrescens because this weed species was least susceptible to the influence of post-dew temperature. These findings suggest that temperature during the infection process (dew-period temperature) had a greater effect on the development of $E$. monoceras on Echinochloa spp. than did post-infection temperature (post-dew temperature). Although no similar study on the relationship between dew-period temperature and post-dew temperature has been reported in other commercial and/or potential bioherbicide pathosystems, results in this study support findings for crop diseases $(4,21)$. These results also indicate that if a sufficient dew period was established after inoculation, or if the dew requirement was overcome or bypassed through artificial inoculation techniques,

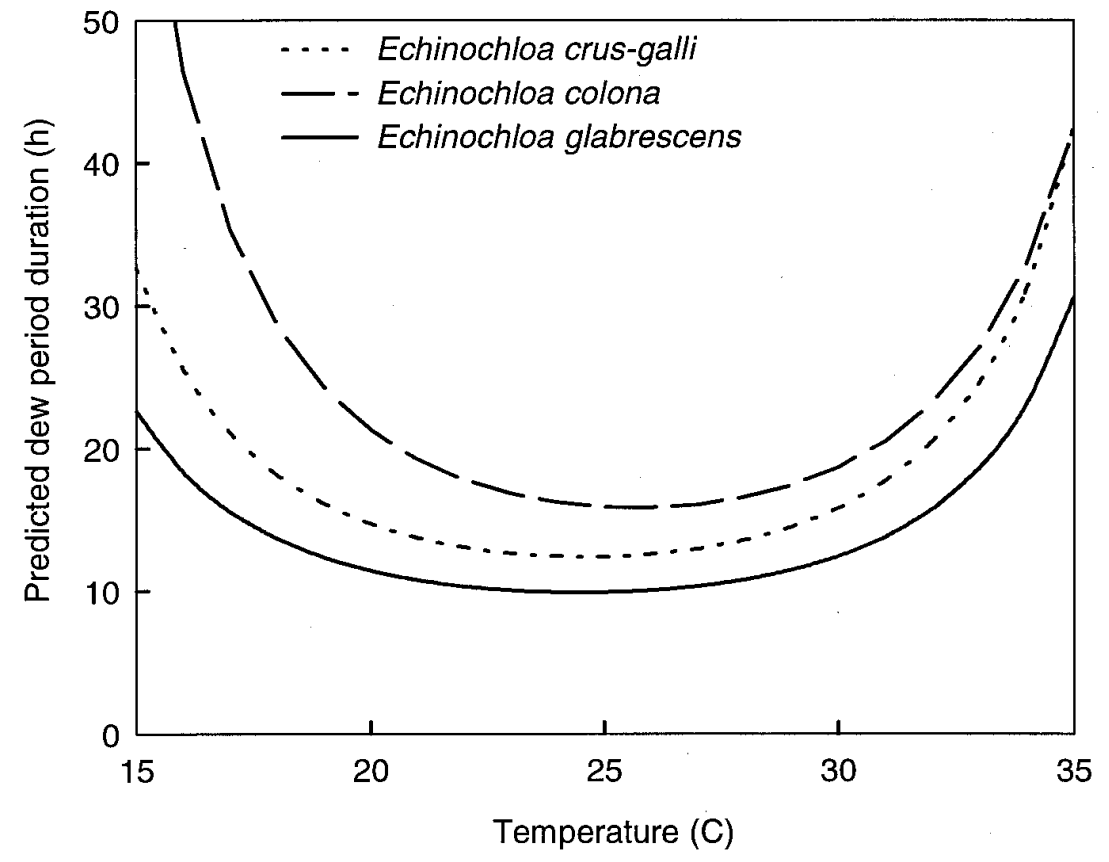

Fig. 5. Effect of dew-period temperature on the predicted dew period required to provide $100 \%$ disease severity on three Echinochloa spp. caused by Exserohilum monoceras, expressed as percent plant mortality 10 days after inoculation. The relationship was best described by the following equations. (i) Echinochloa crus-galli: $\ln D=(M+15.1039) /\left(-36.1946+6.5039 T-0.1323 T^{2}\right),(P=$ $\left.0.0001, r^{2}=0.7213\right)$; (ii) Echinochloa colona: $\ln D=(M+33.45) /\left(-47.14+7.44 T-0.145 T^{2}\right),(P=$ $\left.0.0001, r^{2}=0.7828\right)$; (iii) Echinochloa glabrescens: $\ln D=(M+3.7930) /(-35.0961+6.5739 T-$ $\left.0.1344 T^{2}\right),\left(P=0.0001, r^{2}=0.9254\right)$; where $M=$ mortality $(\%), D=$ dew period, and $T=$ dew-period temperature. Percent mortality data were arc sine-transformed before analysis. 
such as more efficient formulations or application methods (30), post-dew temperature would no longer be a limiting factor for the control of Echinochloa spp. by $E$. monoceras.

The minimum dew period to achieve $100 \%$ mortality was $12 \mathrm{~h}$ for E. crus-galli, $16 \mathrm{~h}$ for E. colona, and $8 \mathrm{~h}$ for E. glabrescens. These dew period requirements are similar to those reported for other bioher-
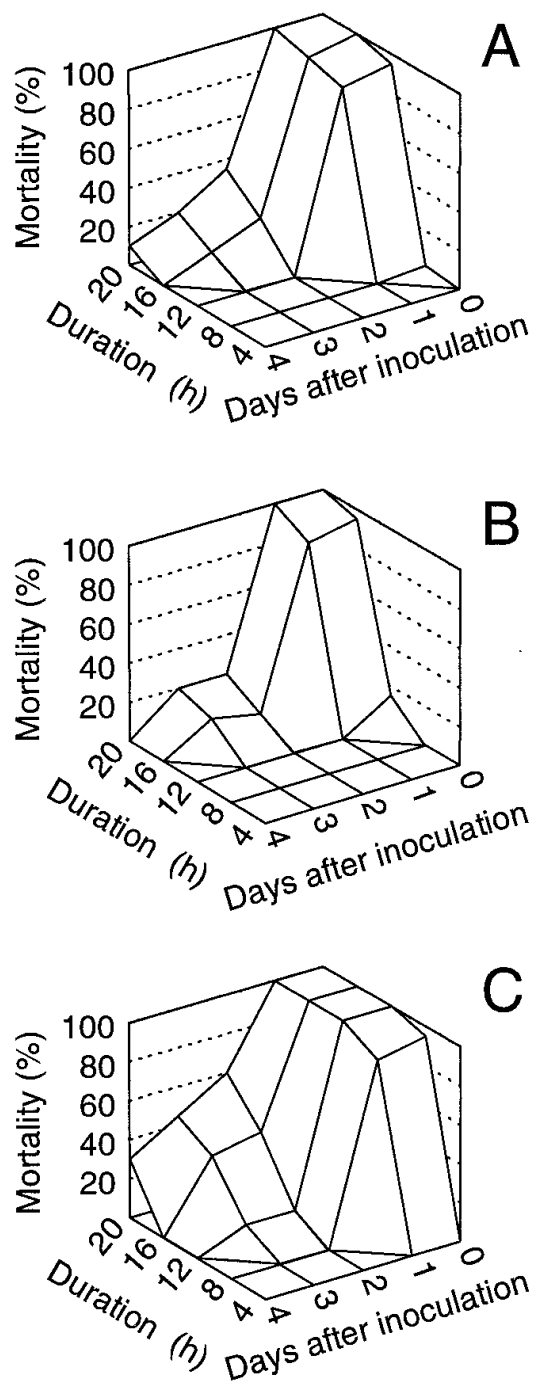

Fig. 6. Effect of delaying initial dew period on disease development caused by Exserohilum monoceras on (A) Echinochloa crus-galli, (B) E. colona, and (C) E. glabrescens, expressed as percent plant mortality 10 days after inoculation. Seedlings at the 1.5-leaf stage were sprayed with a conidial suspension of E. monoceras at a rate of $5 \times 10^{7}$ conidia $/ \mathrm{m}^{2}$. Data from two trials were not pooled because variances were not homogeneous. Points represent means of four replicates. The relationships were best described by the following equations: (A) $Y=$ $-25.22+6.82 P-1.62 P D+0.38 D^{3}, r^{2}=$ 0.8462 ; (B) $Y=-9.31+2.06 P-0.06 P^{2} D+$ $0.01 P^{3}, r^{2}=0.8506$; and (C) $Y=9.68-7.47 D$ $+5.17 P-0.81 P D, r^{2}=0.7768$; where $Y=$ mortality (\%), $D=$ days after inoculation, and $P$ $=$ dew period. Percent mortality data were arc sine-transformed before analysis. bicides and potential bioherbicides including Colletotrichum gloeosporioides f. sp. aeschynomene (20), Fusarium lateritium (1), Alternaria cassiae A. M. M. Jurair \& A. Khan (23), and C. gloeosporioides f. sp. malvae (9). TeBeest (19) suggested that dew period requirements of $16 \mathrm{~h}$ or longer could limit the practical use of fungi as biological control agents for weeds. Therefore, as in other bioherbicide pathosystems, dew period is a limiting factor for the control of Echinochloa spp., especially $E$. colona, by E. monoceras. Fortunately, the limitation of dew period for development of E. monoceras on Echinochloa spp. can be overcome or bypassed by formulating inoculum as an oil emulsion or by the application of a dry-powder formulation that floats conidia on the water surface (30).

The interaction between dew-period temperature and duration demonstrated that the dew period requirement was moderated by dew-period temperature. The predicted curves (Fig. 5) of minimal dew period for $100 \%$ mortality for each species flatten out over the temperature range of 20 to $30^{\circ} \mathrm{C}$. Dew periods of 12 to $16 \mathrm{~h}$ for E. crus-galli, 16 to $21 \mathrm{~h}$ for E. colona, and 10 to $12 \mathrm{~h}$ for E. glabrescens, respectively, were required for E. monoceras to achieve $100 \%$ mortality over this relatively broad temperature range. However, at dew-period temperatures below $20^{\circ} \mathrm{C}$ or above $30^{\circ} \mathrm{C}$, the dew requirement increased significantly for all three Echinochloa spp. The majority of bioherbicide studies place an emphasis on the application of biocontrol agents at times that favor the onset of dew formation $(11,19,23)$. The findings in this study strongly suggest that application of biocontrol agents should also take into account the ambient temperature at the time the biocontrol agents are applied. For $E$. monoceras to control Echinochloa spp., application of the fungus should not be carried out when night temperatures are

Table 1. Effect of repetitive dew periods on mortality and reduction in dry weight of Echinochloa crus-galli inoculated with Exserohilum monoceras $^{\mathrm{y}}$

\begin{tabular}{lcc}
\hline $\begin{array}{l}\text { Dew period } \\
\text { (h/day) }\end{array}$ & $\begin{array}{c}\text { Mortality } \\
(\%)\end{array}$ & $\begin{array}{c}\text { Dry weight } \\
\text { reduction }(\%)\end{array}$ \\
\hline 0 & $0 \mathrm{c}^{\mathrm{z}}$ & $10.0 \mathrm{~d}$ \\
6 & $0 \mathrm{c}$ & $23.8 \mathrm{c}$ \\
$6 ; 6$ & $0 \mathrm{c}$ & $42.6 \mathrm{~b}$ \\
$6 ; 6 ; 6$ & $5 \mathrm{c}$ & $59.1 \mathrm{~b}$ \\
$6 ; 6 ; 6 ; 6$ & $70 \mathrm{~b}$ & $90.0 \mathrm{a}$ \\
12 & $100 \mathrm{a}$ & $100.0 \mathrm{a}$ \\
$12 ; 12$ & $100 \mathrm{a}$ & $100.0 \mathrm{a}$ \\
24 & $100 \mathrm{a}$ & $100.0 \mathrm{a}$ \\
\hline
\end{tabular}

y Seedlings at the 1.5-leaf stage were sprayed with a conidial suspension of $E$. monoceras at $5 \times 10^{7}$ conidia $/ \mathrm{m}^{2}$. Data from two trials were not pooled because variances were not homogeneous. Data represent means of four replicates.

${ }^{\mathrm{z}}$ Values having the same letter are not significantly different according to Duncan's multiple range test at the 5\% significance level. expected to be below $20^{\circ} \mathrm{C}$ or above $30^{\circ} \mathrm{C}$.

A few infections occurred on inoculated Echinochloa seedlings that did not receive a dew period. Similarly, dry periods of up to $24 \mathrm{~h}$ beginning immediately after inoculation did not adversely affect the weed control efficacy of $E$. monoceras if sufficient dew subsequently occurred. Similar results were reported on the biocontrol of Senna obtusifolia (L.) H. Irwin \& Barneby (sicklepod) by Alternaria cassiae, in which a delay of 2 days in the occurrence of dew was tolerated without adversely affecting the efficacy of the pathogen (23). Therefore, field application is not restricted to late afternoons or early evenings as is usually recommended for bioherbicide pathogens $(11,19)$.

Repetitive dew periods have been reported to shorten the optimal dew period required for efficient control of Senna obtusifolia by Alternaria cassiae (23). Similar results were observed in our study, i.e., shorter repetitive dew periods $(6 \mathrm{~h}$ rather than 16 or $24 \mathrm{~h}$ of continuous dew), more closely simulating field conditions than a single long dew period, enhanced the control of all three Echinochloa spp. These results were confirmed by field observations in which foliar applications of conidial suspensions of E. monoceras containing $0.05 \%$ Tween 20 reduced plant dry weight by approximately $5 \%$ at 7 DAI and $50 \%$ at 28 DAI (data not shown).

Yang and TeBeest (26) proposed a model for control efficacy of bioherbicides in which efficacy was composed of primary infections established by the application of inoculum and secondary or postapplication infections. E. monoceras has poor dispersal ability and the precise role of secondary infections for control of Echinochloa spp. by E. monoceras is yet unknown (29). When the inoculum was formulated as an oil emulsion or when applied as a dry powder, the level of primary infection increased significantly and 90\% mortality was achieved at 14 to 20 DAI (29). Therefore, an adequate formulation can greatly reduce the environmental dependency of E. monoceras and increase its potential as a bioherbicide.

\section{ACKNOWLEDGMENTS}

This work was conducted under a memorandum of agreement between the International Rice Research Institute (IRRI) and McGill University. The work was funded by the United Nations Development Programme (UNDP) grant no. GLO/91/001/ A/01/42 to IRRI. Financial support to the second author from IRRI and McGill University is appreciated. Technical assistance of Maria Roberta Miranda and Danny Lucillo is acknowledged. We thank T. C. Paulitz and A. DiTommaso for their constructive suggestions on the conduct of the research and manuscript revision.

\section{LITERATURE CITED}

1. Boyette, C. D., and Walker, H. L. 1985. Factors influencing biocontrol of velvetleaf ( $\mathrm{Abu}$ tilon theophrasti) and prickly sida (Sida spinosa) with Fusarium lateritium. Weed Sci. 33:209-211. 
2. De Datta, S. K. 1981. Principles and Practices of Rice Production. John Wiley and Sons, New York.

3. Draper, N. R., and Smith, H. 1981. Applied Regression Analysis. 2nd ed. John Wiley and Sons, New York.

4. Filajdić, N., and Sutton, T. B. 1992. Influence of temperature and wetness duration on infection of apple leaves and virulence of different isolates of Alternaria mali. Phytopathology 82:1279-1283.

5. Gomez, K. A., and Gomez, A. A. 1984. Statistical Procedures for Agricultural Research. 2nd ed. John Wiley and Sons, New York.

6. Holcomb, G. E. 1982. Constraints on disease development. Pages 61-71 in: Biological Control of Weeds with Plant Pathogens. R. Charudattan and H. L. Walker, eds. John Wiley and Sons, New York

7. Holm, L. G., Plucknett, D. L., Pancho, J. V., and Herberger, J. P. 1977. The World's Worst Weeds. Distribution and Biology. The University Press of Hawaii, Honolulu.

8. IRRI. 1993. Program Report for 1992. Int. Rice Res. Inst., Manila, Philippines. pp. 177178.

9. Makowski, R. M. D. 1993. Effect of inoculum concentration, temperature, dew period, and plant growth stage on disease of round-leaved mallow and velvetleaf by Colletotrichum gloeosporioides f. sp. malvae. Phytopathology 83:1229-1234.

10. Matsunaka, S. 1983. Evolution of rice weed control practices and research: World perspective. Pages 5-17 in: Weed Control in Rice. Int. Rice Res. Inst., Manila, Philippines.

11. McRae, C. F., and Auld, B. A. 1988. The influence of environmental factors on anthracnose of Xanthium spinosum. Phytopathology 78:1182-1186.

12. Mercado, B. L., and Talatala, R. L. 1977.
Competitive ability of Echinochloa colona L. against direct-seeded lowland rice. Pages 161165 in: Proc. Asian-Pacific Weed Sci. Soc. Conf., 6th.

13. Moody, K. 1989. Weeds Reported in Rice in South and Southeast Asia. Int. Rice Res. Inst., Manila, Philippines.

14. Moody, K. 1991. Weed control in upland rice with emphasis on grassy weeds. Pages 164178 in: Tropical Grassy Weeds. F. W. G. Baker and P. J. Terry, eds. CAB Int. CASAFA, Wallingford, UK.

15. Rao, A. N., and Moody, K. 1992. Competition between Echinochloa glabrescens and rice (Oryza sativa). Trop. Pest Manage. 38:25-29.

16. SAS Institute Inc. 1985. SAS/STAT Guide for Personal Computers. Version 6 ed. SAS Inst., Cary, NC.

17. Smith, R. J., Jr. 1968. Weed competition in rice. Weed Sci. 16:252-255.

18. Smith, R. J., Jr. 1983. Weeds of major economic importance in rice and yield losses due to weed competition. Pages 19-36 in: Weed Control in Rice. Int. Rice Res. Inst., Manila, Philippines.

19. TeBeest, D. O. 1991. Ecology and epidemiology of fungal plant pathogens studied as biological control agents of weeds. Pages 97-114 in: Microbial Control of Weeds. D. O. TeBeest, ed. Chapman and Hall, New York.

20. TeBeest, D. O., Templeton, G. E., and Smith, R. J., Jr. 1978. Temperature and moisture requirements for development of anthracnose on northern jointvetch. Phytopathology 68: 389-393.

21. Trapero-Casas, A., and Kaiser, W. J. 1992. Influence of temperature, wetness period, plant age, and inoculum concentration on infection and development of Ascochyta blight of chickpea. Phytopathology 82:589-596.

22. Tuite, J. 1969. Plant Pathological Methods: Fungi and Bacteria. Burgess Pub., Minneapo- lis, $\mathrm{MN}$.

23. Walker, H. L., and Boyette, C. D. 1986. Influence of sequential dew periods on biocontrol of sicklepod (Cassia obtusifolia) by Alternaria cassiae. Plant Dis. 70:962-963.

24. Watson, A. K. 1994. Current status of bioherbicide development and prospects for rice in Asia. Pages 195-201 in: Integrated Management of Paddy and Aquatic Weeds in Asia. $\mathrm{H}$. Shibayama, K. Kritani, and J. Bay-Peterson, eds. FFTC Book Ser. No. 45. Food and Fertilizer Technology Centre for Asian and $\mathrm{Pa}$ cific Regions, Taipei, Taiwan

25. Watson, A. K., and Wymore, L. A. 1990 Identifying limiting factors in the biocontrol of weeds. Pages 305-316 in: New Directions in Biological Control: Alternatives for Suppressing Agricultural Pests and Diseases. R. R. Baker and P. E. Dunn, eds. Alan R. Liss, New York.

26. Yang, X. B., and TeBeest, D. O. 1993. Epidemiological mechanisms of mycoherbicide effectiveness. Phytopathology 83:891-893.

27. Yeh, W. H., and Bonman, J. M. 1986. Assessment of potential resistance to Pyricularia oryzae in six rice cultivars. Plant Pathology 35:319-323.

28. Zadoks, J. C., and Schein, R. D. 1979. Epidemiology and Plant Disease Management. Oxford University Press, New York.

29. Zhang, W. M. 1996. Biological control of Echinochloa species with pathogenic fungi. Ph.D. diss. McGill University, Montréal, Québec, Canada.

30. Zhang, W. M., and Watson, A. K. Efficacy of Exserohilum monoceras for the control of Echinochloa species in rice (Oryza sativa). Weed Sci. (In press.)

31. Zhang, W. M., Moody, K., and Watson, A. K. 1996. Responses of Echinochloa species and rice (Oryza sativa) to indigenous pathogenic fungi. Plant Dis. 80:1053-1058. 